\title{
EXPERIMENTAL INVESTIGATION OF A LEADING EDGE COOLING SYSTEM WITH OPTIMIZED INCLINED RACETRACK HOLES
}

\author{
Carlo Carcasci, Bruno Facchini Lorenzo Tarchi \\ Department of Industrial Engineering \\ University of Florence \\ Florence, Italy \\ email: Iorenzo.tarchi@htc.de.unifi.it
}

\author{
Nils Ohlendorf \\ Alstom \\ Baden, Switzerland
}

\begin{abstract}
An experimental survey of a leading edge cooling scheme was performed to measure the Nusselt number distribution on a large scale test facility simulating the leading edge cavity of an high pressure turbine blade. Test section is composed by two adjacent cavities, a rectangular supply channel and the leading edge cavity. The cooling flow impinges on the concave leading edge internal walls, by means of an impingement array located between the two cavities, and it is extracted through showerhead and film cooling holes. The impingement geometry is composed by a double array of circular or shaped holes. The aim of the present study is to investigate the heat transfer performance of two optimized impingement schemes in comparison with a standard one with circular and orthogonal holes. Both the optimized arrays have inclined racetrack shaped holes and one of them has also a converging shape. Measurements were performed by means of a transient technique using narrow band Thermo-chromic Liquid Crystals (TLC). Jet Reynolds number was varied in order to cover the typical engine conditions of these cooling systems $\left(\operatorname{Re}_{\mathrm{i}}=15000\right.$ 45000). Results are reported in terms of detailed 2D maps, radial and tangential averaged Nusselt numbers.
\end{abstract}

\section{NOMENCLATURE}

A Jet cross-section area

d Impingement jet diameter

D Target surface curvature

h, HTC Heat transfer coefficient

$\mathrm{k}$ Thermal conductivity

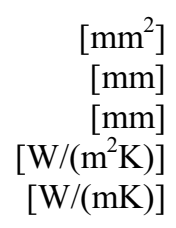

$\begin{array}{ll}1 & \text { Hole length } \\ \mathrm{m} & \text { Mass flow rate } \\ \mathrm{Ma} & \text { Mach number } \\ \mathrm{n} & \text { Impingement jets number } \\ \mathrm{Nu} & \text { Nusselt number } \\ \mathrm{p} & \text { Pressure } \\ \mathrm{R} & \text { Radius of curved target plate } \\ \mathrm{Re} & \text { Reynolds number } \\ \mathrm{S}_{\mathrm{x}} & \text { Tangential-wise pitch } \\ \mathrm{S}_{\mathrm{y}} & \text { Radial-wise pitch } \\ \mathrm{t} & \text { Time } \\ \mathrm{T} & \text { Temperature } \\ \mathrm{x} & \text { Tangential-wise direction } \\ \mathrm{y} & \text { Radial-wise direction } \\ \mathrm{Z} & \text { Jet-to-target surface distance }\end{array}$

[mm]

$[\mathrm{kg} / \mathrm{s}]$

$[-]$

$[-]$

$[-]$

$[\mathrm{Pa}]$

[mm]

$[-]$

$[\mathrm{mm}]$

[mm]

[K]

$[\mathrm{mm}]$

$[\mathrm{mm}]$

$[\mathrm{mm}]$

\section{Greeks}

$\alpha \quad$ Thermal diffusivity

$\beta \quad$ Leading edge opening angle

$\left[\mathrm{m}^{2} / \mathrm{s}\right]$

Relative measurement error

[deg]

$\varepsilon$

$\mu \quad$ Dynamic viscosity

$\rho \quad$ Density 
W

Wall

\section{Acronyms}

FC Film Cooling

LE Leading Edge

PMMA Polymethyl Methacrylate

SH Shower-head

TLC Thermo-chromic Liquid Crystals

\section{INTRODUCTION}

The Turbine Inlet Temperature (TIT) increase represents a key factor to achieve higher thermal efficiency and higher power output of a gas turbine. However, as the TIT increases, the heat loads management becomes a crucial aspect, therefore the design of an efficient turbine cooling system is a key factor in guaranteeing adequate component life times, especially when the airfoils leading edge region is considered.

Heat transfer in the leading edge region of a turbine airfoil is dependent upon the interacting effects of jet impingement, film coolant extraction and convection over the portions of the surface not directly impacted by the jets. The parameters that may affect the flow and heat transfer include impinging jet Reynolds number, jet size and distribution, leading edge opening angle, jet nozzles to the leading edge surface spacing, film cooling hole distribution (number, location, angle), and distribution of the total cooling flow among the available flow paths. The possible effects of these and other parameters are compounded by their interaction. The presence of cooling extraction holes will inevitably modify the flow field in the leading edge cavity by providing new flow paths for the cooling fluid. Such flowfield modification could affect the heat transfer performances in a positive or negative way. In the open literature, large amount of works can be found on the heat transfer performances of such complex cooling systems.

Regarding jet impingement, pioneer studies were performed by Metzger et al. [1] [2], Kercher and Tabakoff [3], Martin [4], Florschuetz et al. [5] [6], Goldstein et al. [7]. They presented recovery factor, effectiveness and heat transfer coefficient for different nozzle-to-plate distances, Reynolds numbers and temperature differences. These investigations focused on local enhancement of the convective heat transfer rates subjected to impinging jets in the case of relatively uniform nozzle spacing in both the radial and span-wise directions.

Jet impingement cooling over concave surfaces, comparable to a leading edge cooling scheme, was studied by Metzger et al. [8,9] and Hrycak [10]. They focused on the relationship between the heat transfer coefficient and the shape of the target surface. In 1969, Chupp et al. [11] performed an experimental study on a single row of impingement jets on a scaled model of a leading edge. The authors correlated the heat transfer results to encompass the effects of jet-to-target surface spacing (z/d), jet-to-jet spacing $(\mathrm{S} / \mathrm{d})$, and target surface curvature $(\mathrm{D} / \mathrm{d})$ valid between jet Reynolds numbers of 3000 and 15000, thus providing a correlation for the averaged Nusselt number at the stagnation point. Very interesting contributions were provided by Bunker and Metzger [12]. They performed detailed heat transfer measurement using temperature sensitive coatings, varying impingement jet holes spacing, jet-to-target spacing, leading edge radius of curvature and jet Reynolds number. Using the same test rig, Bunker and Metzger [13] studied the effects of film cooling mass flow extraction on the LE internal cooling. The authors found an increase of the HTC with aligned jet holes and extraction holes

arrangement, while staggered configurations led to a decrease of the HTC. The authors also pointed out that the mass flow rate split amongst the extraction holes does not affect the HTC distribution.

In the late 90s Lee at al. [14] performed experimental heat transfer measurements for a single impinging jet using a steady state liquid crystal technique. The dependence of impingement heat transfer on jet Reynolds number was explored for Reynolds numbers between 11000 and 50000. The authors found that for $\mathrm{Re}_{\mathrm{j}}=11000$ and 23000 , the maximum stagnation Nusselt number was apparent at jet-to-target plate spacing of $\mathrm{z} / \mathrm{d}=6$ with a slight reduction in the stagnation Nusselt number for smaller $\mathrm{z} / \mathrm{d}$ values. Furthermore, a heat transfer peak offset from the stagnation point was observed at $\mathrm{z} / \mathrm{d}=2$ and $\mathrm{z} / \mathrm{d}=4$. A sharp transition from a laminar to turbulent boundary layer on the target surface resulted in a sudden, localized increase in heat transfer. Fenot et al. [15] explored jet impingement on a concave target surface with the jet Reynolds numbers varying from 10000 to 23000. Nusselt number peaks offset from the stagnation point were observed at $\mathrm{z} / \mathrm{d}=2$ and $\mathrm{z} / \mathrm{d}=5$. A decrease in the spacing between jets caused an increase in overall heat transfer. Carcasci et al. [16] studied impingement flow field using several experimental techniques.

Since 2001, Taslim et al. [17, 18] have performed a series of experimental and numerical analyses of a complex leading edge cooling system configuration. The geometry is characterized both by jet impingement on a curved surface, and film cooling hole extraction. The most interesting findings are that showerhead film holes extraction and target surface roughness represent the leading parameters for the HTC enhancement with respect to inflow/outflow arrangement and jet-to-target spacing. In a more recent contribution, Taslim and Bethka [19] reported an experimental and numerical analysis of the effect of different flow arrangement in the feeding channel and inside the leading edge cavity on the heat flux. They found higher heat transfer coefficient values on the leading edge side walls than on the nose. They also confirmed what was previously found by Kercher and Tabakoff [3], i.e. that the crossflow in the feeding channel leads to a reduction of the impinging jet effectiveness. In one of their latest works, Elebiary and Taslim [20] performed a numerical study, supported by experiments, on a LE geometry characterized by racetrack shaped crossover holes. They found that the Nusselt number along the leading edge channel is strongly affected by the flow arrangement. 


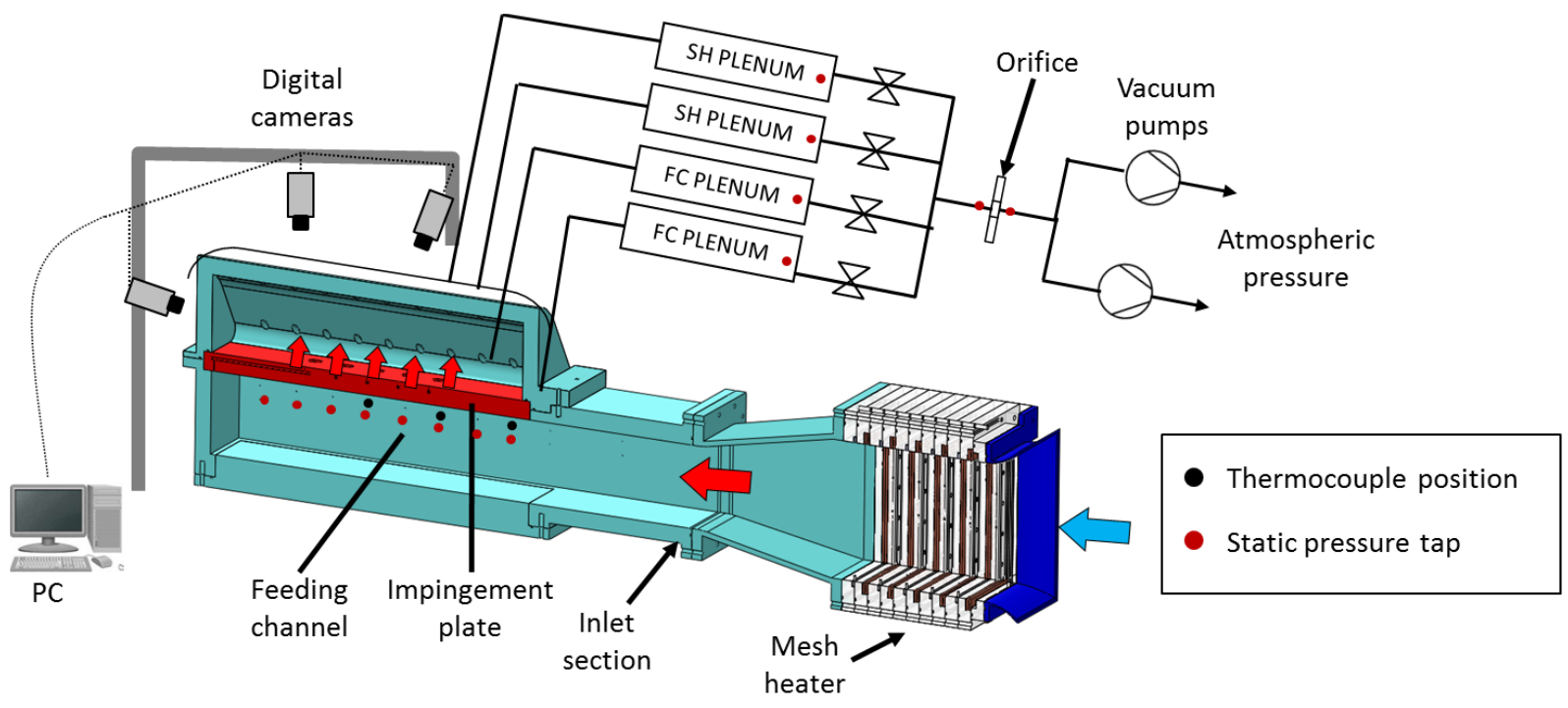

FIGURE 1: Test rig scheme

In recent years, Wright et al. [21-23] have been carrying out intensive studies on the dependence of the Nusselt number varying impingement jet geometries, jet-to-jet spacing, jet-totarget surface distance and jet temperature. They have found higher Nusselt numbers with racetrack impingement holes and negligible effects due to jet temperature variations. Moreover, by decreasing the width of the jet-to-jet distance and shortening the distance between the jets and target surface, they have found an increase of the heat transfer. For small $\mathrm{z} / \mathrm{d}_{\mathrm{j}}$ and $\mathrm{S}_{\mathrm{y}}$ values, local Nusselt number peaks were offset from the center of the jet core, meaning the highest heat transfer occurs outside of the stagnation region. In order to increase the readiness level of experimental studies on such kinds of cooling systems, the European Research project called ERICKA (Engine Representative Internal Cooling Knowledge and Application) has been recently promoted. The present work, performed in the framework of this project, deals with a real-engine leading edge cooling system characterized by impingement cooling holes, shower-head and film cooling extraction holes. Such research has already provided detailed Nusselt number distributions, as published by Andrei et al. [24], focusing on the effect of the external crossflow, asymmetric mass flow extraction from the pressure and suction sides and large fins in the cavity, on the Nusselt number distribution and by Facchini et al. [25], focusing on the effects of impingement jet to jet spacing on the internal heat transfer coefficient. Results from this paper were also used as a starting point for the definition of the present geometries.

So, the aim of the present paper is to investigate the performance in terms of heat transfer coefficient and distribution of two optimized geometries. The innovative aspect of such arrays is that holes have a racetrack shape and are inclined respect to the impingement plate, moreover the second one has also a slightly converging hole. Results are compared with a reference geometry with orthogonal circular holes keeping fixed the holes spacing.

\section{EXPERIMENTS}

\section{Experimental Apparatus}

The present activity was performed at the Department of Industrial Engineering of the University of Florence - DIEF. The experimental setup (depicted in the scheme of figure 1) consists in an open-loop suction type test rig. The vacuum system is composed of four rotary vane vacuum pumps: two with a capacity of $900 \mathrm{~m}^{3} / \mathrm{h}$ each and two with $300 \mathrm{~m}^{3} / \mathrm{h}$ each. The mass flow rate is controlled by the speed of the pumps.

The mass flow rate is measured according to the standard EN ISO 5167-1, by means of an orifice located at the end of the wind tunnel with a measurement accuracy below $2 \%$. Inlet flow rate was varied between $0.04-0.14 \mathrm{~kg} / \mathrm{s}$ in order to reach the desired values of jet Reynolds number.

The flow temperature is measured with several T-type thermocouples located in the plenum channel, near the impingement jets inlet. Thermocouples are connected to a data acquisition/switch unit (Agilent 34970A) with a measurement accuracy of $0.5 \mathrm{~K}$. Two pressure scanners Scanivalve DSA 3217 with temperature compensated piezoresistive relative pressure sensors measure the static pressure in 32 different locations with a maximum accuracy of $8.3 \mathrm{~Pa}$.

In order to have a complete view of the whole measurement section, three digital cameras (Sony XCDSX90CR) were used. The cameras simultaneously record a sequence of raw bitmap images $(1280 \times 480$ pixel $-7 \mathrm{fps})$ from the TLC painted surface on a PC via IEEE 1394b interface. One camera records the leading edge curved region while the other two record the lateral walls. The illumination system is composed by four $8 \mathrm{~W}$ white LED arrays (120 LED) of 750-800 lumen, to ensure a uniform illumination on the tested surface. 

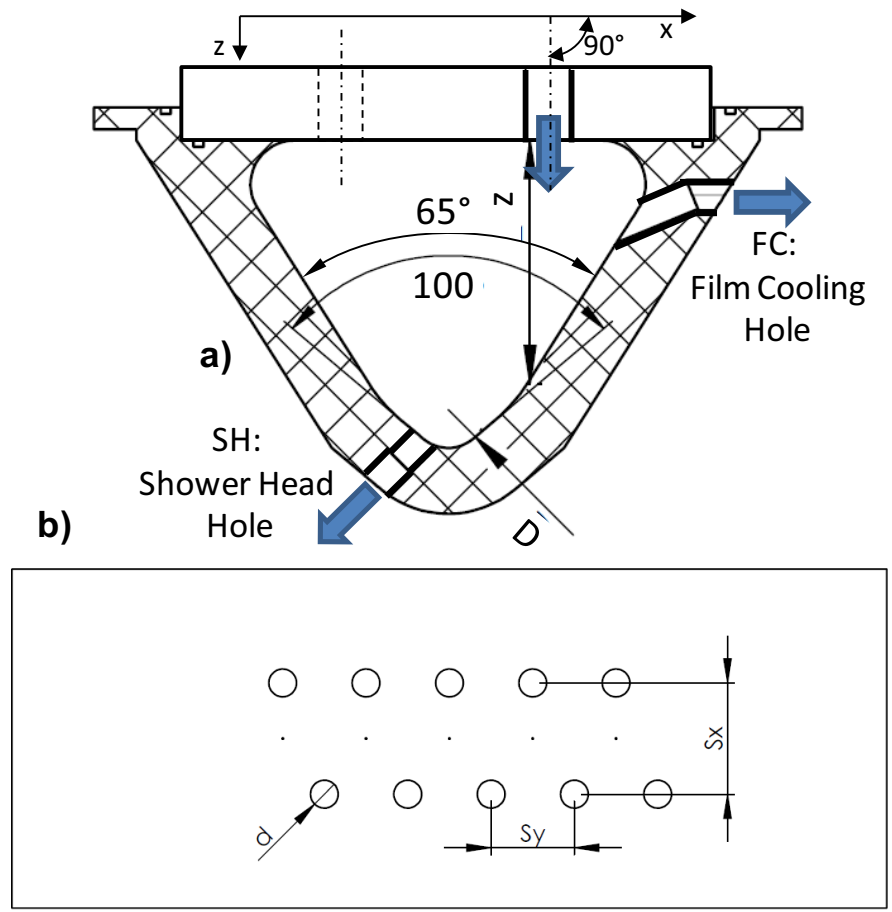

FIGURE 2: External (a) and internal impingment geometry (b) of reference geometry

Wall temperature and, consequently, the heat transfer coefficient, was measured by means of narrow band TLC supplied by Hallcrest Ltd and active from $40^{\circ} \mathrm{C}$ to $41^{\circ} \mathrm{C}$. Crystals are thinned with water and sprayed with an airbrush onto the tested surfaces; successively, a water base black paint is sprayed to obtain a black background.

The test rig is composed of an inlet section where air at atmospheric pressure and ambient temperature passes through a ten stages mesh heater in order to provide an instantaneous and uniform temperature step change to the inlet mass flow. The mesh used to build the heater is made by an AISI304 stainless steel woven wire mesh with wire diameter of $0.030 \mathrm{~mm}$ and a distance between the wires of $0.039 \mathrm{~mm}$. The mesh heater is fed by two DC power supplies with a maximum electrical power of $10 \mathrm{~kW}$ which is then transferred as thermal power to the fluid.

Downstream the heater there is a contraction and then the flow enters a rectangular supply channel $(\mathrm{LxWxH}=$ $930 \times 150 \times 215 \mathrm{~mm})$ and finally impinges onto the internal surface of the leading edge cavity through the impingement geometry. The flow in the leading edge cavity is then extracted by means of four arrays of circular holes simulating the showerhead and film cooling extraction. Each array of extraction holes is connected to an independent plenum where pressure level is tuned throttling several gate valves. Measurements are performed extracting the same mass flow from the four plenums (i.e. the mass flow extraction is practically the same from each $\mathrm{SH} / \mathrm{FC}$ hole). Such condition has been set thanks to a previous characterization of each plenum, determining a flow function between the plenum itself and the leading edge, so during the experiments it is possible to estimate the mass flow of each row measuring the pressure difference between the leading edge and each plenum and finally checking the global value with the orifice measurements.

The whole measurement section is entirely made of transparent PMMA $\left(\mathrm{k}_{\mathrm{PMMA}}=0.19 \mathrm{~W} / \mathrm{mK}\right)$, in order to obtain the required optical access for TLC measurements and to limit thermal losses across the material.

\section{TLC Calibration}

The TLCs have been calibrated to replicate the same optic conditions of the real test: the green color peak intensity is found at $40.5^{\circ} \mathrm{C}$ and it is the most repeatable and evident effect, so it was used as the event temperature in the data reduction procedure. The TLC calibration was performed following the steady state gradient method (Chan et al. [26]). The calibration setup is made of a $4.5 \mathrm{~mm}$ thin aluminum rectangular plate, housing seven thermocouples, sprayed with black background paint and then the TLCs. One of the edges is heated by an electric heater, while the other is cooled by air. The whole apparatus is housed in an insulated base. The digital camera and illumination system are placed at the same distance and inclination of the real test, so as to replicate the exact optic conditions. A linear temperature gradient will appear on the TLC surface: once steady conditions are reached, a single picture is sufficient to relate the color information acquired by the camera with the temperature measured by the thermocouples. The experiments were repeated several times in order to increase global accuracy.

\section{Geometries}

The geometries studied are a typical cold-bridge geometry of a leading edge of a blade. The blade geometry (external) is shown in figure 2a: it has a circular leading edge shape followed by a double inclination flat surface, the first part with 100deg opening angle, the second one with 65deg opening angle.

\begin{tabular}{|l|ccc|}
\hline & $\begin{array}{c}\text { Base }=\text { G090 } \\
\text { Fig.2 }\end{array}$ & $\begin{array}{c}\text { G105 } \\
\text { Fig3a }\end{array}$ & $\begin{array}{c}\text { G100c } \\
\text { Fig3b }\end{array}$ \\
\hline Jet inclination & $90^{\circ}$ & $105^{\circ}$ & $100^{\circ}$ \\
Impingement angle & $32.5^{\circ}$ & $47.5^{\circ}$ & $42.5^{\circ}$ \\
Jet shape & Circular & Racetrack & Racetrack \\
Hole shape & Constant & Constant & Convergent \\
& cross-section & cross-section & cross-section \\
Out-In jet area ratio & 1.0 & 1.0 & 0.5 \\
Jet position & Aligned with & Aligned with & Aligned with \\
& FC holes & SH holes & SH holes \\
Radial pitch: $\mathrm{S}_{\mathrm{y}} / \mathrm{d}_{\mathrm{i}}$ & 3.0 & 3.1 & 3.1 \\
Tangent. pitch: $\mathrm{S}_{\mathrm{x}} / \mathrm{d}_{\mathrm{i}}$ & 5.0 & 5.1 & 5.1 \\
Jet-surface dist.: $\mathrm{z} / \mathrm{d}_{\mathrm{j}}$ & 4.53 & 3.3 & 3.3 \\
Hole length: $1 / \mathrm{d}_{\mathrm{i}}$ & 1.65 & 1.71 & 1.68 \\
\hline
\end{tabular}

Table 1: Main dimensions of tested geometries 


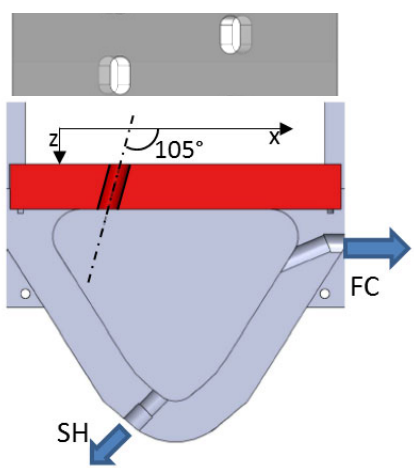

(a) G105 geometry

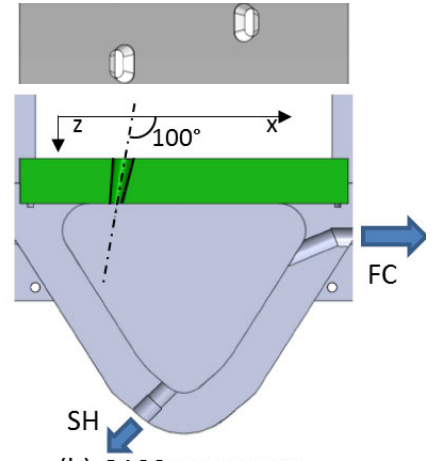

(b) G100c geometry
FIGURE 3: New geometries: $G 105$ with $105^{\circ}$ impinging angle (a) and G100c with $100^{\circ}$ impinging angle and convergence hole (b)

The base geometry (G090) has been chosen as a reference as it was the best performing one between various investigated arrays [25]. Varying impingement jet shape, jet injection angle and the relative position between jet and extraction holes, leaded to the definition of two new impingement geometries, G105 and G100c.

Main dimensionless parameters of the internal impingement geometries are reported in Table 1, while the external and internal geometries are depicted in figure 3.

Geometries G105 and G100c are characterized by racetrack impingement jets with a hydraulic diameter of $d_{j}=19.45 \mathrm{~mm}$. As illustrated in Figure 3, jets are inclined with respect to the x direction: $G 105$ jets are inclined by $105^{\circ}$ with a constant cross-section area, while $6100 \mathrm{c}$ jets are inclined by $100^{\circ}$ and have a convergent cross-section area with an outlet jet diameter of $d_{j, \text { out }}=0.71 d_{j}$.

Moreover, differently from baseline geometries, the relative position between the impingement jets and the extraction holes is inverted, so the jets are now aligned with the shower-head holes.

\section{Experimental procedure and test conditions}

Heat transfer tests were performed using a transient technique. Before starting the experiment, the total mass flow rate, corresponding to the impingement jet Reynolds number, is set by changing the speed of the pumps and keeping the model at constant ambient temperature. As soon as pressure and mass flow reach steady conditions, cameras start recording frames and the heater is switched on to start the transient test. The transient test ends when TLCs reach the green peak intensity on the whole surface. The transient method for detailed heat transfer coefficient distribution is based on transient heating, assuming one-dimensional conduction in a semi-infinite solid (Ireland et al. [27], Camci [28]). The transient response of the surface temperature is given by Equation 1:

$$
\frac{T_{w}(t)-T_{w, i}(t=0)}{T_{j}(t)-T_{w, i}(t=0)}=1-\exp \beta^{2} \cdot \operatorname{erfc}(\beta)
$$

where

$$
\beta=\frac{h \cdot \sqrt{\alpha_{P M M A} \cdot t}}{k_{P M M A}}
$$

where $T_{w}$ is the local time-dependent wall temperature measured by detecting TLC green, $T_{i}$ the initial wall temperature, $T_{j}$ the impingement jet temperature, $h$ the unknown local heat transfer coefficient, $t$ the time required to reach TLC green peak at any location of the tested surface, $\alpha$ and $\mathrm{k}$ are the thermal diffusivity and thermal conductivity of the PMMA, respectively. Equation 1 can be applied only under the hypothesis of a semi-infinite flat wall, so for the geometry studied in the present work the hypothesis can be considered valid only for the lateral walls of the model. Even though a mesh heater was used, a perfect step change in the flow temperature cannot be realized, therefore the principle of superposition was applied to model the gas temperature history in the data reduction procedure. For the leading edge region, an explicit finite-difference method in cylindrical coordinates was used in order to solve one-dimensional transient conduction across the PMMA, to take into account the effect of surface curvature.

The minimum time to reach TLC green peak intensity was about 10 seconds after turning on the mesh heater, while the time duration of the test was between 150 and 250 seconds, depending on the $\mathrm{Re}_{\mathrm{j}}$ and main flow temperature. This time interval guarantees the TLC activation on the whole tested area and it ensures the validity of the semi-infinite solid assumption (Graham and Rhine [29]).

The main investigated parameters, $\mathrm{Re}_{\mathrm{j}}$ and $\mathrm{Nu}$ are defined using the holes hydraulic diameter. A total of 28 different tests were performed with varying jet Reynolds, $\mathrm{Re}_{\mathrm{j}}$, from 10000 to 50000 which can be rewritten as a feed cavity Reynolds number from 9700 to 48600 . Jet Reynolds number is calculated considering steady conditions of mass flow rate, pressure and temperature after the switch on of the heater. The result of the post processing procedure is composed by three $2 \mathrm{D}$ heat transfer maps, one for each camera. The map given by the camera focused on the curved surface is then unrolled in order to obtain the $\mathrm{x}$-dimension as curvilinear abscissa. Finally the three maps are overlapped in correspondence to the showerhead holes.

\section{Experimental Uncertainty}

The uncertainty analysis was performed following the ASME [30] standard based on Kline and McClintock's [31] method and takes into account the uncertainty of the following parameters: TLC calibration temperature, starting temperature, TLC green peak time, jet temperature, PMMA conductivity, density and specific heat. Higher uncertainties in the evaluation of the Nusselt number were found at lower response times (i.e. higher $\mathrm{Nu}$ values), $\mathrm{e}_{\mathrm{Nu}, \max }=13.4 \%$, while for the other $\mathrm{HTC}$ values the uncertainly was below $10 \%$. As regards $\mathrm{Re}_{\mathrm{j}}$ typical uncertainty is $\mathrm{e}_{\mathrm{Re}}=1.76 \%$. 

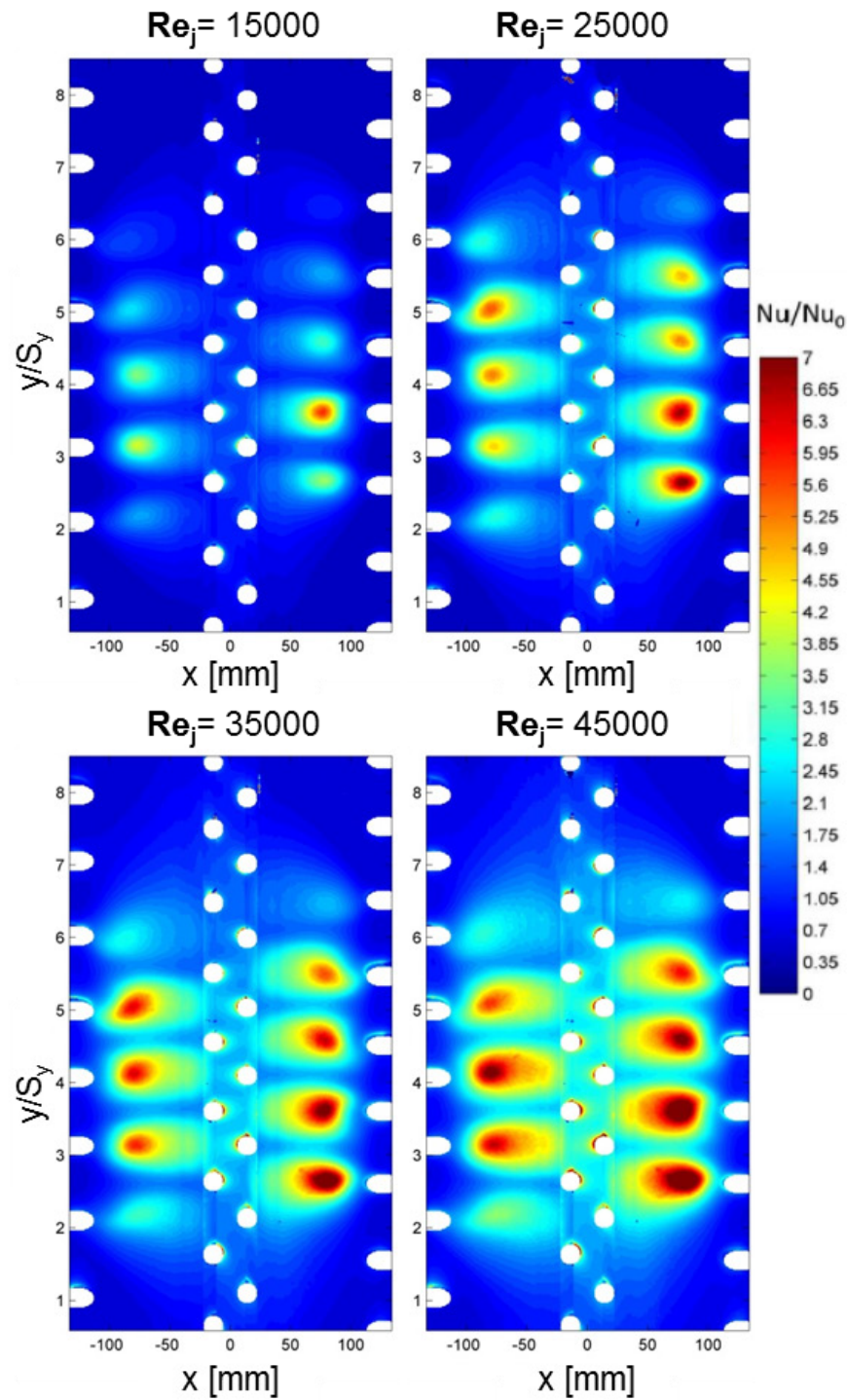

FIGURE 4: Nusselt contour plots of G090 geometry

\section{RESULTS}

Figure 4 shows the two-dimensional Nusselt number contours for the four tested jet Reynolds numbers $\left(\mathrm{Re}_{\mathrm{j}}=15000\right.$, 25000, 35000 and 45000) of the baseline geometry G090. Results are expressed in terms of $\mathrm{Nu} / \mathrm{Nu}_{0}$ where $\mathrm{Nu}_{0}$ is 33.39 and it is fixed for all the geometries. Nusselt peaks are almost circular in the stagnation region, while a slight distortion is present from one side due to the extraction of the coolant from the shower-head holes and in the SH direction because of the interaction of the jet with the inclined wall which leads to a wider portion of the impingement area affected by the heat transfer increase. In the central area the presence of the showerhead extraction holes guarantees a more uniform distribution of the Nusselt number.
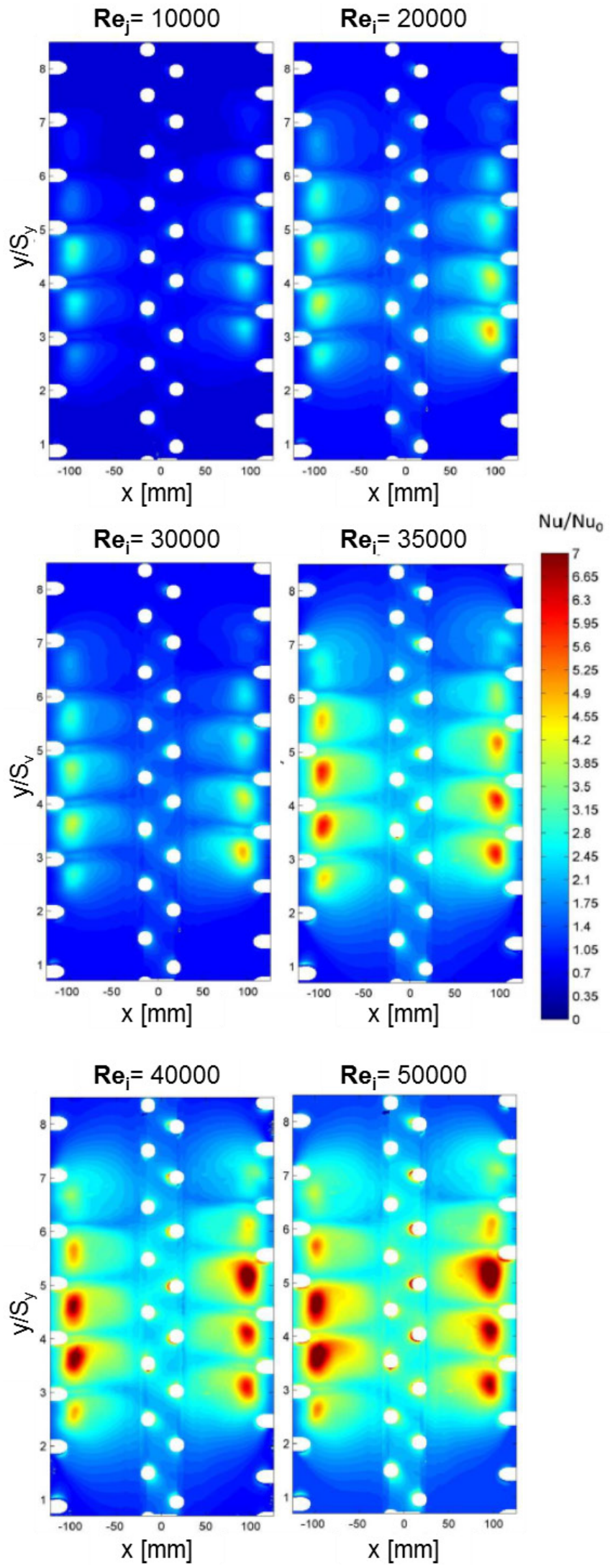

FIGURE 5: Nusselt contour plots of G105 geometry 

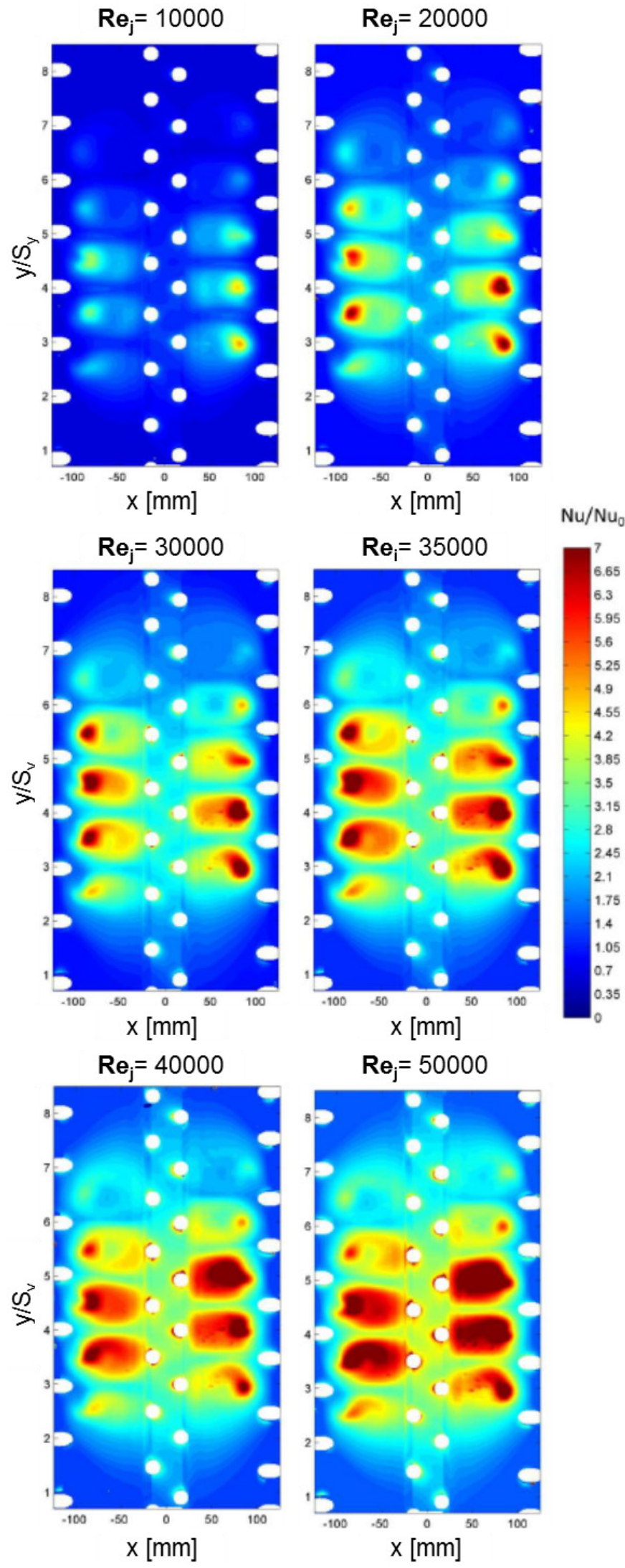

FIGURE 6: Dimensionless Nusselt contour plots of G100c geometry

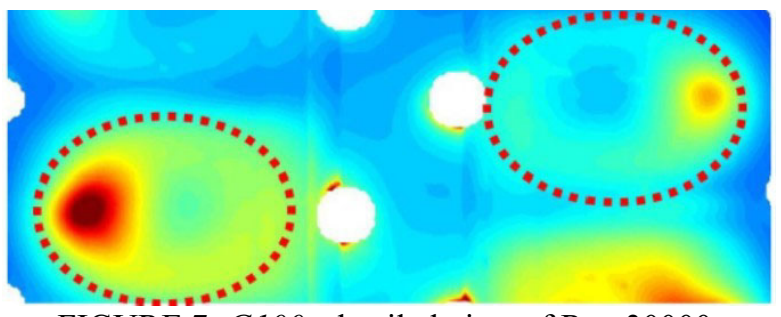

FIGURE 7: $G 100 c$ detailed view of $\mathrm{Re}_{\mathrm{j}}=30000$.

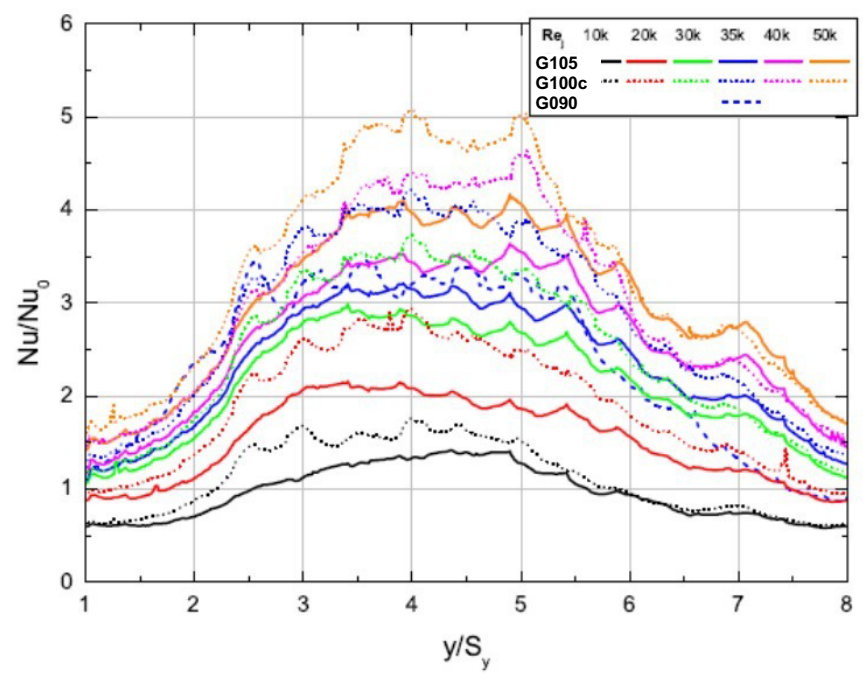

FIGURE 8: Dimensionless averaged Nusselt number for G105 and $G 100 c$ : radial direction

Figure 5 shows the two-dimensional Nusselt number contours for the six tested jet Reynolds numbers of geometry G105. The maps confirm the strong dependence of the Nusselt number with the jet Reynolds number, as already seen in the baseline geometries results. For each contour plot it is evident that the number of Nusselt peaks is related to the number of the impingement jets and the 10 peaks generated by the impingement jets are well defined with a racetrack shape.

Jet stagnation regions are located very close to the film cooling extraction holes due to the inclination of impingement jets. In particular, the hole inclination combined with the inclined target surface lead to a decrease of the resulting jet-totarget surface distance $\mathrm{z} / \mathrm{d}_{\mathrm{j}}=3.3$, with a related increase in the Nusselt number in the stagnation region with respect to the values measured at geometry $G 090$.

Even if the jet stagnation region is very close to the film cooling extraction holes, a relevant heat transfer increase has been also found along the lateral walls and in the central curved region, due to the extraction from the showerhead holes together with the positive pressure gradient generated by the inclined side walls.

As regards the geometry $G 100 c$ results, Figure 6 shows the two-dimensional Nusselt number contours for all the tested jet Reynolds numbers. The convergent shape of the impingement holes leads to a sharp increase in the Nusselt number in the 
stagnation region, due to the higher momentum of the jets. Important to note is the shape of the jet stagnation region. Contrary to what was seen in the two-dimensional contours of G105, in this case each jet generates a different stagnation region shape. In particular, some areas assume an annular ring shape, as can be seen in the detailed view shown in Figure 7.

The peak near the film cooling extraction holes indicates the jet stagnation point, then a separation seems to occur with a reattachment near the shower-head extraction holes, resulting in an enlargement of the area scoured by the impinging cooling flow. The plots reported in figure 8 and 9 are very useful to compare geometries G105 and G100c. Looking at figure 8 and to the 2D contour plots too, some clarifications should be done to explain the variations of $\mathrm{Nu}$ in the radial direction that is mainly present in the first and in the last injection holes. The reason are mainly two: first of all is that the impingement array does not cover completely the leading edge cavity, as a consequence, first and last holes probably suffer from the mixing with cold air which is recirculated inside the cavity for $y / S_{y}<2$ and $y / S_{y}>7$. The second one is that the mainstream air which fed the last holes in radial direction $\left(y / S_{y}>7\right)$ is partially mixed with cooler air recirculated inside the plenum (see Figure 1). Both those effects cause a slight but non predictable jet temperature reduction which causes the lower Nusselt values in that areas. To avoid such spurious effects, comparisons in the tangential direction (Figure 9) have been made considering the surface from $\mathrm{y} / \mathrm{S}_{\mathrm{y}}=3$ to 5 . The baseline geometry $G 090$ at $\mathrm{Re}_{\mathrm{j}}=35 \mathrm{k}$ is given as a reference. Along the radial direction, geometry $G 100 c$ has given higher Nusselt number at all the tested Reynolds numbers with a global increase of about 20$30 \%$ with respect to geometry $G 105$.

The averaged Nusselt number trends in the tangential direction highlight well the differences between the two geometries in terms of maximum Nusselt number and its distribution. The first evidence of this is the peak location, very close to the film cooling extraction arrays for geometry G105, while it is more cantered along the lateral walls for geometry G100c, having also an overall higher Nusselt number values.

Another interesting aspect is the variation of the Nusselt number along the lateral walls. In fact, as already seen in the two-dimensional contours, G100c guarantees a quite uniform Nusselt number increase on the lateral sides, with a less marked variation from $\mathrm{x}=75$ to $25 \mathrm{~mm}$ compared to the trend found with geometry G105 that is characterized by a sharp decrease from the stagnation region to the shower-head extraction. Last, but not least, geometry $G 100 \mathrm{c}$ is the only geometry among all the tested ones, that has led to a substantial Nusselt number increase also in the central curved region, with an increase of about $25-30 \%$ at all the tested jet Reynolds numbers.

Finally, to summarize all the discussed results, the spatially averaged Nusselt numbers reported in figure 10 clearly show that the while the optimized geometry G105 is in line with the reference $G 090$, the optimized array $G 100 c$ with inclined and convergent racetrack holes leads to higher average heat transfer rates.

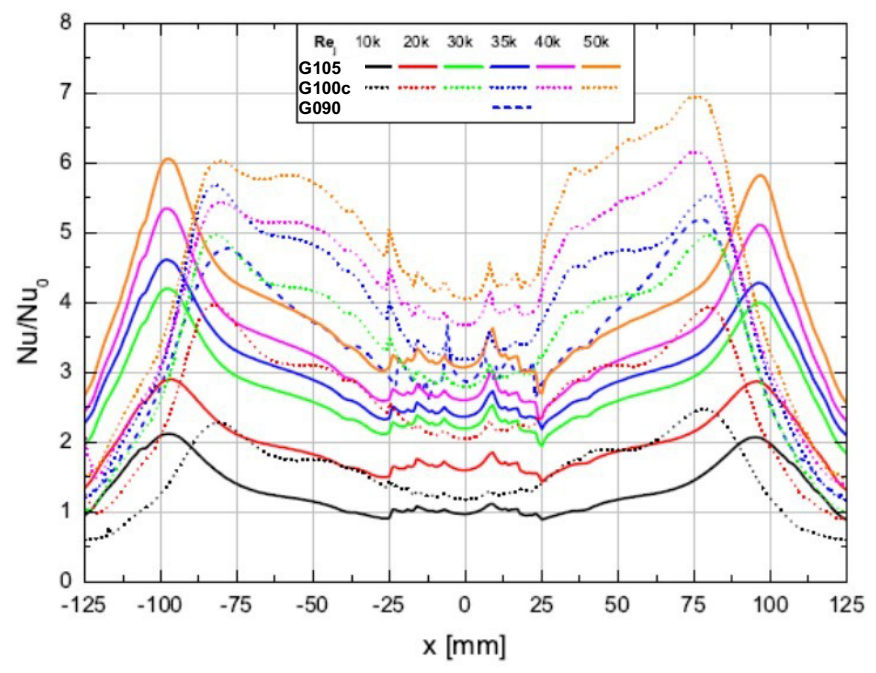

FIGURE 9: Dimensionless averaged $\left(3<\mathrm{y} / \mathrm{S}_{\mathrm{y}}<5\right)$ Nusselt number for $G 105$ and $G 100 c$ : tangential direction

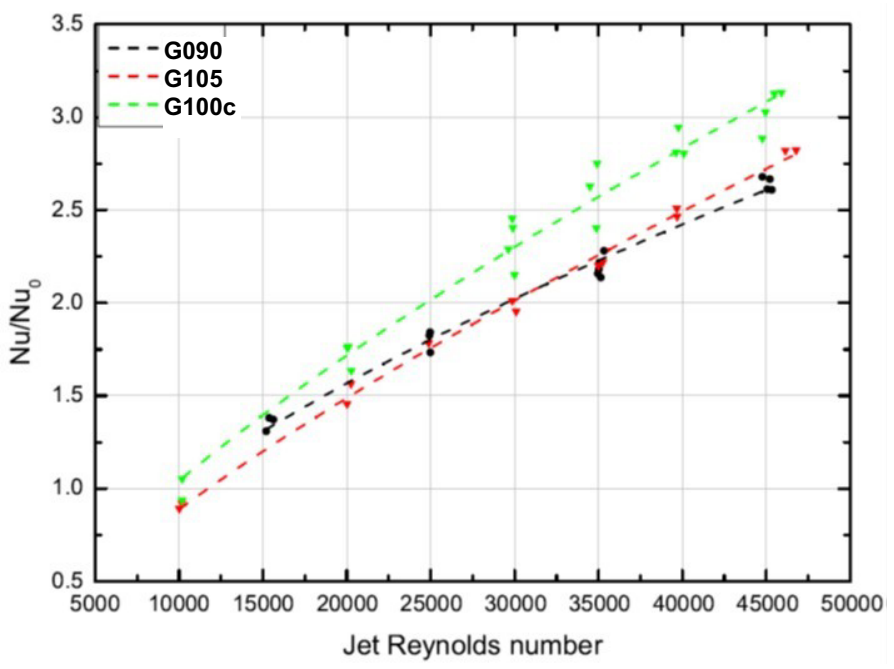

FIGURE 10: Spatially dimensionless averaged Nusselt number for $G 105, G 100 c$ and $G 090$

\section{CONCLUSION}

An intensive experimental study was performed to measure the internal Nusselt number in a leading edge cavity.

The investigation concerns three different internal impingement geometries with different hole shape and it is aimed to their characterization in terms of Nusselt number distribution and average values. Tests were performed varying jet Reynolds numbers from $\mathrm{Re}_{\mathrm{j}}=15000$ to 45000 . Measurements were carried out using a transient technique with narrow band TLC.

A baseline geometry with circular staggered holes (G90) have been compared with two optimized arrays (G105 and G100c) with racetrack inclined (respectively 105deg and 
100deg) holes. Geometry G100c additionally implements a converging shape.

The final aim of the investigation is the characterization and the validation of these two innovative impingement solutions in terms of internal heat transfer performance.

Taking 35,000 $\mathrm{Re}_{\text {jet }}$ as reference, it is possible to highlight two main effects comparing G090 with the first optimized solution G105: a more unique Nusselt distribution and secondly a lower HTC peak level. Reasons for this behavior are a shift of the impingement jet holes between the film cooling holes and secondly a decrease in $\mathrm{z} / \mathrm{d}_{\mathrm{j}}$ for G105 (due to the inclination of the impingement hole). This would normally lead to an increase in HTC max value but the effect is equalized using race track instead of circular holes. In conclusion, even though the Nusselt level has not improved for G105 compared to G090, an improvement in the HTC distribution can be found.

For geometry G100c, the racetrack imprint is still visible on the target surface, and the peak location is practically the same of the reference G090 array. The effect of the heat transfer enhancement in the stagnation region is extended in the tangential direction leading to a $10-20 \%$ increase of the average Nusselt values, assessing G100c as the best performing configuration. Reasons for this behavior are mainly due to the converging shape of the impingement holes and the connected velocity increase of the impingement flow.

\section{ACKNOWLEDGMENTS}

The Authors wish to thanks PhD F. Maiuolo.

The research leading to these results has received funding from the European Union Seventh Framework Program (FP7/2007-2013) under grant agreement n. 233799 (ERICKA).

\section{REFERENCES}

[1] Metzger, D. E., Yamashita, T., and Jenkins, C. W., 1969. "Impingement Cooling of Concave Surfaces with Lines of Circular Air Jets". Journal of Engineering for Power, 93 , pp. 149-155.

[2] Metzger, D., Takeuchi, D., and Kuenstler, P., 1973. "Effectiveness and Heat Transfer with Full-Coverage Film Cooling". ASME Journal of Engineering for Power, 95, pp.180-184.

[3] Kercher, D. M., and Tabakoff,W., 1970. "Heat Transfer by a Square Array of Round Air Jets Impinging Perpendicular to Flat Surface Including the Effect of Spent Air". ASME Journal of Engineering for Power, 92, pp. 73-82.

[4] Martin, H., 1977. "Heat and Mass Transfer Between Impinging Gas Jets and Solid Surfaces". Advances in Heat Transfer, 13, pp.1-60.

[5] Florschuetz, L., Truman, C., and Metzger, D., 1981. "Streamwise Flow and Heat Transfer Distributions for Jet Array Impingement with Crossflow". ASME Journal of Heat Transfer, Vol.103, pp.337-342.

[6] Florschuetz, L., Metzger, D., Su, C., Isoda, Y., and Tseng, H., 1984. "Heat Transfer Characteristics for Jet Arrays Impingement with Initial Crossflow". ASME Journal of Heat Transfer, 106 , pp. 34-41.
[7] Behbahani, A., and Goldstein, R., 1983. "Local Heat Transfer to Staggered Arrays of Impinging Circular Air Jets". ASME Journal of Engineering for Power, Vol.105, pp.354-360.

[8] Metzger, D. E., Yamashita, T., and Jenkins, C. W., 1969. "Impingement Cooling of Concave Surfaces with Lines of Circular Air Jets". Journal of Engineering for Power, Vol.91, pp.149-158.

[9] Metzger, D. E., Baltzer, R. T., and Jenkins, C. W., 1972. "Impingement Cooling Performance in Gas Turbine Airfoils Including Effects of Leading Edge Sharpness". Journal of Engineering for Power, 94 , pp. 219-225.

[10] Hrycak, P., 1981. "Heat Transfer from a Row of Impinging Jets to Concave Cylindrical Surfaces". International Journal of Heat Mass Transfer, 24 , pp. 407-419.

[11] Chupp, R. E., Helms, H. E., McFadden, P. W., and Brown, T. R., 1969. "Evaluation of Internal Heat Transfer Coefficients for Impingement Cooled Turbine Blades". Journal of Aircraft, 6 ,pp. 203-208.

[12] Metzger, D. E., and Bunker, R. S., 1990. "Local Heat Transfer in Internally Cooled Turbine Airfoil Leading Edge Regions: Part I - Impingement Cooling without Film Coolant Extraction". J Turbomach, 112, pp. 451-458.

[13] Metzger, D. E., and Bunker, R. S., 1990. "Local Heat Transfer in Internally Cooled Turbine Airfoil Leading Edge Regions: Part II - Impingement Cooling with Film Coolant Extraction". J Turbomach, 112, pp. 459-466.

[14] Lee, D. H., Chung, Y. S., and Won, S. Y., 1999. "The Effect of Concave Surface Curvature on Heat Transfer from a Fully Developed Round Impinging Jet". International Journal of Heat and Mass Transfer, 42 , pp. 2489-2497.

[15] Fenot, M., Dorignac, E., and Vullierme, J. J., 2008. “An Experimental Study on Hot Round Jets Impinging on a Concave Surface". International Journal of Heat and Fluid Flow, 29 , pp. 945-956.

[16] Carcasci, C., 1999; "An Experimental Investigation on Impinging Jets Using Visualisation Methods", Édition Elsevier, International Journal of Thermal Sciences (Revue Générale de Thermique), Volume 38, Issue 9, October 1999, Pages 808-818, Parigi (Francia), ISSN: 12900729

[17] Taslim, M. E., Pan, Y., and Spring, S. D., 2001. "An Experimental Study of Impingement on Roughened Airfoil Leading-Edge Walls with Film Holes". Journal of Turbomachinery, Vol.123, pp.766-773.

[18] Taslim, M. E., Bakhtari, K., and Liu, H., 2003. "Experimental and Numerical Investigation of Impingement on a Rib-Roughened Leading-Edge Wall”. ASME TurboExpo Paper, GT2003-38118.

[19] Taslim, M. E., and Bethka, D., 2007. "Experimental And Numerical Impingement Heat Transfer In An Airfoil Leading-Edge Cooling Channel with Crossflow". ASME TurboExpo Paper, GT2007-28212.

[20] Elebiary, K., and Taslim, M. E., 2011. "Experimental/Numerical Crossover Jet Impingement in an Airfoil Leading-Edge Cooling Channel". ASME Paper (GT2011-46004). 
[21] Jordan, C. N., Wright, L. M., and Crites, D. C., 2012. "Impingement Heat Transfer On A Cylindrical, Concave Surface with Varying Jet Geometries". ASME Paper, (GT2012-68818).

[22] Martin, E. L., Wright, L. M., and Crites, D. C., 2012. "Impingement Heat Transfer Enhancement on a Cylindrical Leading Edge Model with Varying Jet Temperatures". ASME Paper (GT2012-68817) .

[23] Martin, E. L., Wright, L. M., and Crites, D. C., 2012. "Computational Investigation of Jet Impingement on Turbine Blade Leading Edge Cooling with Engine-Like Temperatures". ASME Paper (GT2012-68811).

[24] Andrei, L., Carcasci, C., Soghe, R. D., Facchini, B., Maiuolo, F., Tarchi, L., and Zecchi, S., 2013. "H Heat Transfer Measurements in a Leading Edge Geometry with Racetrack Holes and Film Cooling Extraction". J. Turbomach. 135(3), 031020 (9 pages), doi: 10.1115 / 1.4007527.

[25] Facchini, B., Maiuolo F., Tarchi, L., Ohlendorf N., 2013; "Experimental Investigation on the Heat Transfer of a Leading Edge Cooling System: effects of jet-to-jet spacing and showerhead extraction", Proc. of ASME Turbo Expo 2013, GT2013-94759, June 3-7, 2013, San Antonio, Texas, USA.
[26] Chan, T. L., Ashforth-Frost, S., and Jambunathan, K., 2001. "Calibrating for Viewing Angle Effect During Heat Transfer Measurements on a Curved Surface". International Journal of Heat and Mass Transfer, 44, pp.2209-2223.

[27] Ireland, P. T., Wang, Z., and Jones, T. V., 1993. "Liquid Crystal Heat Transfer Measurements". In Measurements Techniques, Lecture Series 1993-05. von Karman Institute for Fluid Dynamics.

[28] Camci, C., 1995. "Liquid Crystal Thermography". In Temperature Measurements, Lecture Series 1996-07. von Karman Institute for Fluid Dynamics.

[29] Graham, D., and Rhine, J., 2000. "The Design of Transient Wall Heating Experiments for the Determination of Convective Heat Transfer Using Liquid Crystal Thermography". ASME Paper (GT2000-0658).

[30] ASME, 1985. "Measurement Uncertainty". In Instrument and Apparatus, vol. ANSI/ASME PTC 19.1-1985 of Performance Test Code. ASME.

[31] Kline, S. J., and McClintock, F. A., 1953. "Describing Uncertainties in Single Sample Experiments". Mechanical Engineering, 75 Jan , pp. 3-8. 